\title{
ZnO Nanostructure Thin Film Transistors on Plastic Substrate Prepared by Solution Method and PH Sensing Properties
}

\author{
$1^{\text {st }}$ Feri Adriyanto \\ Dept. Electrical Engineering \\ Universitas Sebelas Maret \\ Surakarta, Indonesia \\ feri.adriyanto@staff.uns.ac.id \\ $3^{\text {rd }}$ Mohd Noh Dalimin \\ Dept. of Science, Faculty of Science, Technology and Human \\ Universiti Tun Hussein Onn Malaysia \\ Johor, Malaysia \\ noh@uthm.edu.my
}

\author{
$2^{\text {nd }}$ Mohd Zainizan Sahdan \\ Microelectronics \& Nanotechnology-Shamsuddin Research Centre \\ (MiNT-SRC), \\ Universiti Tun Hussein Onn Malaysia \\ Johor, Maaysia \\ zainizan@uthm.edu.my \\ $4^{\text {th }}$ Muhammad Nizam \\ Dept. Electrical Engineering \\ Universitas Sebelas Maret \\ Surakarta, Indonesia \\ muhammad.nizam@staff.uns.ac.id
}

\begin{abstract}
We fabricated a ZnO nanostructures based TFT on plastic substrate by solution method under low temperature. $\mathrm{ZnO}$ nanostructures were prepared by zinc nitrate hexahydrate, and hexamethylenetetramine. The device shows hard saturation characteristics and exhibits a high off-resistance. The output characteristics devices also shows current saturation and pinch off behavior, in which the high of current saturation obtained $266 \square A$ at $V G S=40 \mathrm{~V}$ and $V D S=42.5 \mathrm{~V}$. The $\mathrm{pH}$ response on the electrical properties was also studied. It was found that the threshold voltage shifted from $10.21 \mathrm{~V}$ to $13 \mathrm{~V}$ as $\mathrm{pH}$ solution gradually increased. The Ion/Ioff for as grown TFTs and TFTs with $p H$ response of 10.21 shifted from $1.86 \times 105$ to $7.03 \times 106$ at $\mathrm{VDS}=20 \mathrm{~V}$. The obtained sensitivity of devices was $1.05 \mathrm{~V} / \mathrm{pH}$.
\end{abstract}

Keywords- ZnO nanostructure, plastic substrate, $p H$ response, electrical behavior of transistors.

\section{INTRODUCTION}

The flexible nano-electronics device is one of the future technologies in the past decade. The development of flexible electronics technology promises both to widerange market and further investigation in which further accelerate and stimulate the development of this exciting field. Recently, flexible nano-electronics device have been extensively studied due to have the advantages and wide range application

Among semiconducting nanostructures, $\mathrm{ZnO}$ have been drawn much attention for the wide-range electronic and optoelectronic applications [1]-[5]. As chemical sensor, $\mathrm{ZnO}$ nanostructure is one of the most promising materials due to it has high surface-to-volume ratio, nontoxicity, chemical stability, electrochemical activity, and high electron communication features [6]. The change $\mathrm{pH}$ will create $\mathrm{H}^{+}$ions and/or $\mathrm{OH}^{-}$in the solution and will release the metal atom in an amphoteric oxide. Since the changes of $\mathrm{pH}$ for very small volumes, the controlling the surface nanostructure morphology is still needed. Although studied of electrical properties of $\mathrm{ZnO}$ nanostructures thin films transistors (TFT) were recently reported [7]-[10], $\mathrm{pH}$ response of $\mathrm{ZnO}$ nanostructures TFT in electrolyte solutions are still under development. As we know that $\mathrm{ZnO}$ is an amphoteric substance, which reacts with either an acid or base of solutions and will generate current variation of TFT. Whereas most nanostructures material as $\mathrm{pH}$ sensors are use $\mathrm{ZnO}$ nanostructures with 80 $\mathrm{nm}$ diameter and $700 \mathrm{~nm}$ length and grown on the tip of borosilicate glass capillary [6] enable the application of highly sensitive of $\mathrm{pH}$ response. Although the effect $\mathrm{pH}$ of the solution to control the sensitive of the $\mathrm{ZnO}$ nanostructures as $\mathrm{pH}$ sensing material has been realized [6],[11], control of $\mathrm{pH}$ value by using release $\mathrm{H}^{+}$ions and/or $\mathrm{OH}^{-}$of the solution to give a high mobility, drain to current on/off ratios and current density, and low threshold voltage of $\mathrm{ZnO}$ nanostructure TFTs is still not well reported. Therefore, these results provide both low temperature growth of $\mathrm{ZnO}$ nanostructure as active channel of flexible TFTs and $\mathrm{pH}$ sensing devices.

In this letter, we report the result obtained the $\mathrm{ZnO}$ nanostructures grown on plastic substrate and then further studied of electrical behavior of TFTs when its response at difference $\mathrm{pH}$ solutions.

\section{EXPERIMENTS}

In The $\mathrm{ZnO}$ nanostructure was fabricated using solutions method and was deposited using zinc nitrate hexahydrate, $\mathrm{Zn}\left(\mathrm{NO}_{3}\right)_{2} .6 \mathrm{H}_{2} \mathrm{O}$ (Alfa Aesar, assay 99.998\%) and hexamethylenetetramine (HMT) $\mathrm{C}_{12} \mathrm{H}_{6} \mathrm{~N}_{4}$ (Alfa Aesar, assay $99+\%)$. The ITO-laminated plastic substrate of PET (Perm Top Co. Ltd., Taiwan) with ITO thickness and resistivity of $175 \mu \mathrm{m}$ and $8 \Omega$ /square, respectively, was used as the plastic substrate of the obtained films. The solutions were stored in a Teflon vessel and kept at 
temperature of $90{ }^{\circ} \mathrm{C}$. The concentrations of $\mathrm{Zn}\left(\mathrm{NO}_{3}\right)_{2} \cdot 6 \mathrm{H}_{2} \mathrm{O}$ and $\mathrm{HMT}$ were kept at an equimolar solution of $0.01 \mathrm{M}$ in $20 \mathrm{ml}$ deionized water solution. The $\mathrm{ZnO}$ growth process was also monitored during 10 hours. The $\mathrm{pH}$ values were adjusted by adding different amounts of $0.10 \mathrm{M}$ natrium-hydroxide $(\mathrm{NaOH})$ into the main solution. Subsequent to each process, the sample was removed from the main solutions before it was finally rinsed (with deionized water and dry nitrogen) and dried in a dry oven at $100{ }^{\circ} \mathrm{C}$ for 2 hours.

The ITO bottom gate of $\mathrm{ZnO}$ nanostructure TFTs were fabricated utilizing selective deposition of ITO by UV photolithography processes on ITO-laminated PET plastic substrate. The $\mathrm{SiO}_{2}$ gate dielectric layer was deposited by using solution method. Based on our group previous study [12], the $\mathrm{SiO}_{2}$ powder was added to hydrofluorosilicic acid $\left(\mathrm{H}_{2} \mathrm{SiF}_{6}\right)$ and mixed with deionized water. Then $0.10 \mathrm{M}$ $\mathrm{H}_{3} \mathrm{BO}_{3}$ was added and the solution was stirred for 20 minutes. Finally, the substrate was immersed into $40{ }^{\circ} \mathrm{C}$ treatment solution during 2 hours growth process. The substrate was then removed from the solution, washed with deionized water, and dried at dry oven at $100{ }^{\circ} \mathrm{C}$ for 2 hours. The ITO source and drain contacts were sputtered, which the channel length $(L)$ and width $(W)$ were $150 \mu \mathrm{m}$ and $1500 \mu \mathrm{m}$, respectively. After finishing the clean process of the ITO-laminated PET substrate, the $\mathrm{ZnO}$ nanostructures based TFTs planar bottom gate was fabricated, and is shown in Fig 1(a).
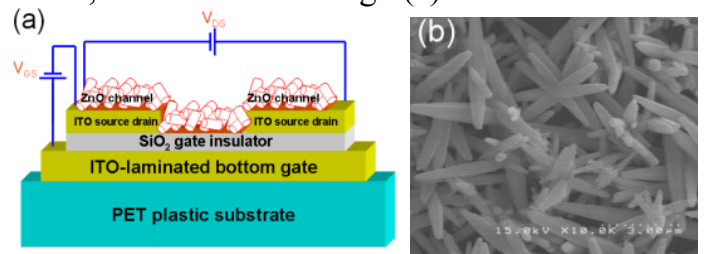

Fig 1. The flexible TFT devices based on $\mathrm{ZnO}$ nanostructure. (a) The schematic illustration devices structure. (b). the corresponding SEM image of $\mathrm{ZnO}$ nanostructure.

Here, we employ the TFTs planar bottom gate structure due to have an advantage such as increasing source and drain resistance causes the limitation the edges of the source and drain, the source and drain resistance due to the bulk conductivity through the channel is minimized.

The ITO bottom gate was produced by wet etching on ITO-laminated of PET substrate with $160 \mu \mathrm{m}$ thick. Then, the $\mathrm{SiO}_{2}$ gate dielectric layer was deposited by using solution method. Finally, before finishing deposit $\mathrm{ZnO}$ nanostructure as a TFT channel onto a $200-\mathrm{nm} \mathrm{SiO}_{2}$ gate dielectric layer, the $175 \mathrm{~nm}$-thick ITO source and drain contacts were sputtered. Meanwhile, the growth temperature was fixed at $95{ }^{\circ} \mathrm{C}$ with the concentration of $\mathrm{Zn}\left(\mathrm{NO}_{3}\right)_{2} \cdot 6 \mathrm{H}_{2} \mathrm{O}$ and HMT were kept at $0.01 \mathrm{M}$ and 0.20 $\mathrm{M}$, respectively. The growth time was kept at 10 .hours. The thickness of the films is $120 \mathrm{~nm}$. The electrical properties of TFTs were measured by using HewletPackard analyzer HP 4156B under atmospheric conditions. The data of $\mathrm{pH}$ response was recorded by using $1 \mu \mathrm{l}$ drop of $\mathrm{NaOH}$ into distillated water.
Figure 1(b) shows the SEM pictures of the $\mathrm{ZnO}$ nanostructures on a $\mathrm{SiO}_{2} / \mathrm{ITO}$-laminated plastic substrate. It was found that the surface morphology of $\mathrm{ZnO}$ shows nanorods, tip-nanorods, and flower-like structure shape. It also can be seen that the $\mathrm{ZnO}$ nanostructures orientation shows the strong intensity of (110) reflection peak. This indicates that most $\mathrm{ZnO}$ have a hexagonal $c$-axis parallel to the substrate surface, which is also consistent with the result obtained form XRD data (not shown)

\section{Results AND Discussion}

Since the capacitance as a function applied voltage $(C$ $-V$ ) measurements of MOS capacitors provide a wealth of information about the structure, the $C-V$ characteristics of $\mathrm{ZnO}$ MOS diode measured at high frequency of $1 \mathrm{MHz}$ and is shown in Fig. 2.

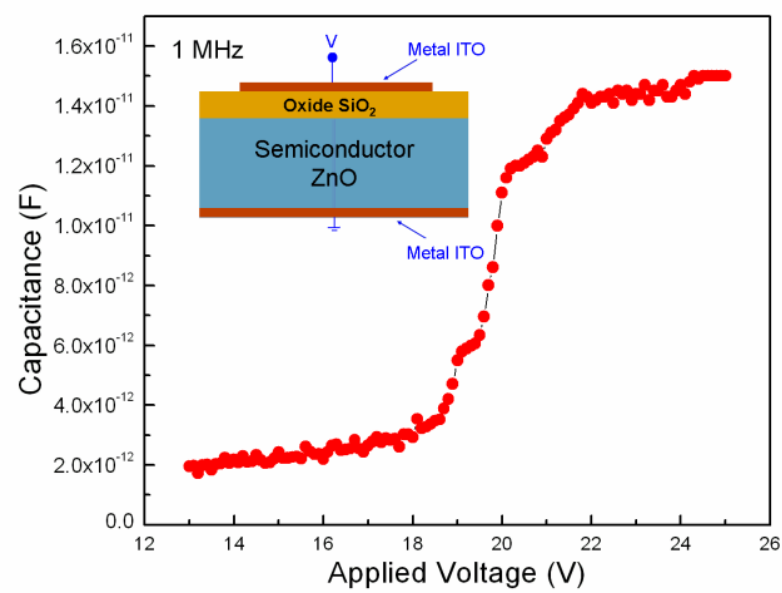

Fig 2. The $C-V$ characteristics of $\mathrm{ZnO}$ MOS-gate capacitor with measured at $1 \mathrm{MHz}$. Inset image of $\mathrm{ZnO}$ MOS structure.

It can be seen that no intermediate phase between oxide and semiconductor. The flatband conditions exist when no charge is present in the semiconductor so that the $\mathrm{ZnO}$ energy band is flat. In here, the flatband capacitance of $14.1 \mathrm{pF}$ was obtained which flatband voltage at $2.9 \mathrm{~V}$. Consequently, the major carrier density is constant.

Figure 3 shows the source-to-drain current $\left(I_{D S}\right)$ as a function of the drain-source voltage $\left(V_{D S}\right)$ curves of $\mathrm{ZnO}$ nanostructure TFT at difference gate-source voltage $\left(V_{G S}\right)$ between 20 and $40 \mathrm{~V}$, respectively. The measurement of the devices was taken at room temperature in the dark with the gate length and width was 150 and $1500 \mu \mathrm{m}$, respectively. Our device shows a hard saturation due to the slope of each $I_{D S}$ curve at large $V_{D S}$ shows a flat curve. The enhancement mode is necessary to create a conductive channel [13]. Our output characteristics devices also shows current saturation and pinch off behavior, in which by the fact that the slope of each $I_{D S}$ curves is nearly constant flat for large $V_{\mathrm{DS}}$ indicating a large source to drain bulk resistance $\left(R_{B}\right)$. 


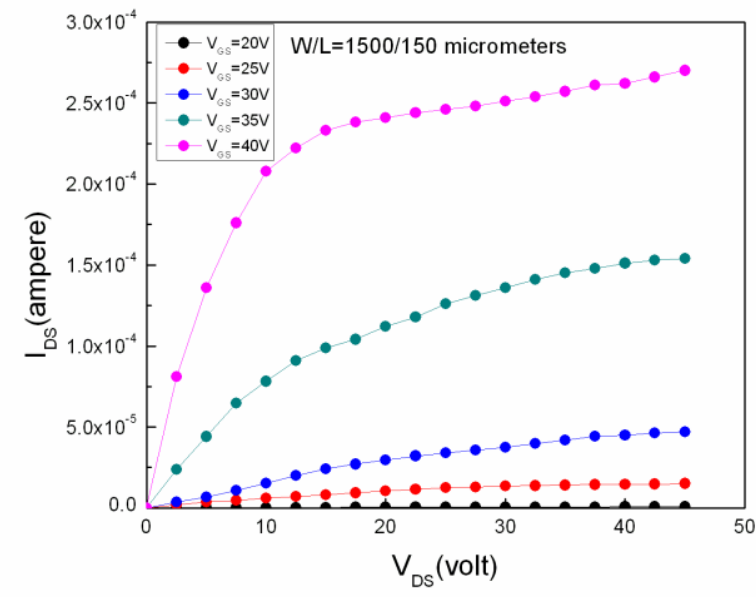

Fig 3. The output characteristics for flexible TFT $\mathrm{ZnO}$ nanostructure. Transfer characteristics for $V_{D S}=20 \mathrm{~V}$.

This indicates that the entire thickness of the $\mathrm{ZnO}$ channel can be depleted of free electrons [14]. It can also be seen that our TFT saturates to a constant $I_{D S}$ for $V_{D S}>>$ $\left(V_{D S}-V_{T}\right)$, which is desirable for most circuit applications. It is interesting to note that the high of current saturation obtained $266 \mu \mathrm{A}$ at $V_{G S}=40 \mathrm{~V}$ and $V_{D S}=42.5 \mathrm{~V}$. It may be caused to pinch off instead of velocity saturation in sub$120 \mathrm{~nm}$ thick $\mathrm{ZnO}$ typical metal-oxide-semiconductor transistors phenomena [15].

In order to study the $\mathrm{pH}$ response on the electrical behavior of $\mathrm{ZnO}$ TFTs, the devices were characterized before (as grown) and after immersing treatment at $\mathrm{pH}$ value of the solution. The transfer characteristic for $\mathrm{ZnO}$ TFT with dropped at $\mathrm{pH}$ of 8.30 and 10.21 , and was compared without immersing treatment was shown in Fig 4. The transfer curves were measured at the same devices with the gate length and width was 150 and $1500 \mu \mathrm{m}$, respectively. It can be seen that the most of transfer curves shows an exponential increase of the drain current. It is interesting to note that the drain current shows linier increase curves at higher gate voltage region. As calculated by a linier region $I_{D S}-V_{G S}$ and saturation region $I_{D S}^{1 / 2}-V$ the voltage $\left(V_{T}\right)$ for as grown TFTs, TFTs with $\mathrm{pH}$ response of 8.30 and 10.21 was 20,15 and $13 \mathrm{~V}$. This result shows the important role regarding influence the electron depletion which affects the gate threshold voltage which proportional to the carrier concentration [16]. In electrolyte solutions, the metal oxide $\mathrm{ZnO}$ surface as active channel of TFT lead to significant hydroxyl group adsorption in which producing $\mathrm{H}^{+}$ions and/or $\mathrm{OH}^{-}$. In general, reducing the device threshold voltage caused by different in work function as resulting of the energy diagram of the MOS structure formed by $\mathrm{ITO}, \mathrm{SiO}_{2}$ and $\mathrm{ZnO}$.

Since the drain current on-to-off ratio $\left(I_{o n} / I_{\text {off }}\right)$ of devices with the enhancement mode behavior is key parameter for novel $\mathrm{pH}$ sensor application, the $I_{\text {on }} / I_{\text {off }}$ was measured at room temperature. The $I_{o n} / I_{\text {off }}$ for as grown
TFTs and TFTs with $\mathrm{pH}$ response of 10.21 shifted from $1.86 \times 10^{5}$ to $7.03 \times 10^{6}$ at $V_{D S}=20 \mathrm{~V}$. This data confirms that the improvement the $I_{o n} / I_{\text {off }}$ due to the channel is induced on the body layer in the on state. The ratio of the average diameter to the length of the $\mathrm{ZnO}$ nanostructures decreased gradually as growth time increased. Therefore, the $I_{\text {on }} / I_{\text {off }}$ of $\mathrm{ZnO}$ TFT increased gradually as $\mathrm{pH}$ value increased. This result agrees well with those several published reports [17]-[19]. It has been further confirm by measurement the field effect mobility $\mu$ of the obtained $\mathrm{ZnO}$ TFTs. In the saturation region, the $\mu$ was described by

$$
I_{D}=\frac{W C_{i}}{2 L} \mu\left(V_{G}-V_{T}\right)^{2}
$$

When the device dropped by solution at $\mathrm{pH}$ of 8.30 and 10.21, the field effect mobility of transistors increased gradually from $9.4 \mathrm{~cm}^{2} / \mathrm{V}$.s to $13.4 \mathrm{~cm}^{2} / \mathrm{V}$.s as $\mathrm{pH}$ solution increased. In order to analyze the material parameters of transistors, the threshold slope of the transistor $(S)$ was performed and calculated by following equation [20]:

$S=\frac{\partial V_{G S}}{\partial\left[\log / I_{D s u b}\right]}=\frac{q k_{B} T N_{T} d_{s}}{C_{G} \log _{10}(e)}$

The threshold slope also shifted from $1.4 \mathrm{~V} /$ decade to $2.6 \mathrm{~V} /$ decade as $\mathrm{pH}$ solution increased. The sensitivity of the devices can be estimated by [21]

Sensitivity $\equiv\left|\frac{\Delta \varphi_{0}}{\Delta p H}\right|=\left|\frac{\Delta V_{T}}{\Delta p H}\right|=\left|\frac{\Delta V_{G S}}{\Delta p H}\right|$

and was $1.05 \mathrm{~V} / \mathrm{pH}$. It may cause the roughness of $\mathrm{ZnO}$ nanostructure surface which resulting defect on interface traps. Consequently, the threshold voltage of devices is quite high [22].

Based on our result above with comparing the other $\mathrm{ZnO}$ nanostructures TFTs that the lowering electrical properties of TFTs due to low-temperature deposition problem of $\mathrm{ZnO}$ nanostructures from aqueous solution in which resulting both insufficiency the thermal energy to induce the local bond of organometallic complexes $\left[\mathrm{Zn}\left(\mathrm{H}_{2} \mathrm{O}\right)_{2}(\mathrm{HMT})_{2}\right]\left(\mathrm{NO}_{3}\right)_{2}$ formed in aqueous solution of $\mathrm{Zn}\left(\mathrm{NO}_{3}\right)_{2}$ and HMT for minimizing grain boundary defects [23]. However, our devices not only open up the possibility for fabrication low-cost flexible TFT but also potentially as $\mathrm{pH}$ sensing.

\section{CONCLUSION}

In summary, we have fabricated the $\mathrm{ZnO}$ nanostructures on plastic substrate as active channel on TFT and study $\mathrm{pH}$ response on electrical behavior of transistors. The $\mathrm{ZnO}$ nanostructures based TFT under low temperature was fabricated and shows improvement in the sub-threshold slope, on/off ratio, and mobility as increasing $\mathrm{pH}$ solutions. These results demonstrated the capability of the device as $\mathrm{pH}$ sensor.

\section{ACKNOLEDGEMENT}

The author would like to thank the Sebelas Maret University for International Research Collaboration Grant 
and the Ministry of Research and Higher Education of Republic of Indonesia for research fellowship.

\section{REFERENCES}

[1] S. Kumar and P. Sharma, Semicond. Sci. Technol., vol. 22, no. 4, pp. L27-L30, April 2007.

[2] J. Tornow and K. Schwarzburg, J. Phys. Chem. C, vol. 111, no. 24 , pp. $8692-8698$, April 20007

[3] A.Z. Sadek, S. Choopun, W. Wlodarski, S.J. Ippolito and K. Kalantar-Zadeh, IEEE Sensors Journal, vol. 7, no. 6, pp. 919. 924, June 2007.

[4] D. Xu, Z. Deng, Y. Xu, J. Xiao, C. Liang, Z. Pei and C. Sun, Phys. Lett. A, vol. 346, issue 1-3, pp. 148-152, October 2005.

[5] S. Ju, K. Lee, M.H. Yoon, A. Facchetti, T.J. Marks and D.B. Janes, Nanotechnology, vol. 18, no. 15, pp. 155201-155207, April 2007.

[6] S.M. Al-Hilli, M. Willander, A. Öst, and P.Strälfors, J. Appl. Phys. vol. 102, issue 8, pp. 084304-084309, Oct 2007.

[7] P.C. Chang, Z. Fan, C.J. Chien, D. Stichtenoth, and C. Ronning, Appl. Phys. Lett, vol. 89, issue 13, pp. 133113133116, Sept. 2006

[8] W. I. Park, J.S. Kim, G.C. Yi, M.H. Bae, and H.J. Lee, Appl. Phys. Lett. vol. 85, no. 21, pp. 5052-5054, Nov. 2004.

[9] J.R. LaRoche, Y.W, Heo, B.S. Kang, L.C. Tien, Y.Kwon, D.P. Norton, B.P. Gila, F.Ren, and S.J. Pearton, J. Electron. Mat, vol. 34, no. 4, pp. 404-408, April 2005.H.C. Cheng, C.F. Chen, and C.C. Lee, Thin Solid Films, vol. 498, no.1-2, pp. 142-145, Mar. 2006

[10] S.M. Al-Hilli, and M. Willander, Appl. Phys. Lett. vol. 89, issue 8 , pp. 173119-173121, Oct 2006.
[11] C.C. Yeh, Y.J. Lin, S.K. Lin, Y.H. Wang, S.F. Chung, L.M Huang and T.C. Wen, J. Vac. Sci. Technol. B, vol. 25, no. 5, pp. $1635-1639$, Oct 2007.

[12] J.H. Kim, B.D. Ahn, C.H. Lee, K.A Jeon, H.S Kang and S.Y Lee, Thin Solid Films, vol. 516, issue 7, pp. 1529-1532, 15 Feb. 2008 .

[13] R.L. Hoffman, B.J. Norris and J.F. Wager, Appl. Phys. Lett. vol. 82, issue 5, pp. 733-735, Feb. 2003.

[14] W.S. Lau, P. Yang, J.Z Chian, V. Ho, C.H. Loh, S.Y. Siah, and L. Chan, Microelectronics Reliability, vol. 49, issue 1, pp. 1-7, Jan. 2009

[15] R. Martel, T. Schmidt, H.R Shen, T. Hertel, and P. Avouris, Appl. Phys. Lett., vol. 73, issue 17, pp. 2447-2449, Oct. 1998.

[16] P. Estrela and P. Migliorato, J. Mat. Chem., vol. 17, issue 3, pp. 219-224, Jan. 2007.

[17] Kargar, Chin. Phys. Lett, vol. 26, no. 6, pp. 060701- 060704, June 2009.

[18] Bartic, B. Palan, A. Campitelli, G. Borghs, Sensor and actuators B, vol. 83, issue 1-3, pp. 115-122, March 2002.

[19] D.W. Greve, Field Effect Devices and Applications: Devices for Portable, Low Power, and Imaging System, $1^{\text {st }}$ ed. Chap. 7, Prentice Hall, 1998.

[20] J.C. Chou and Y.F. Wang, Jpn. J. Appl. Phys. vol. 41, no.10, pp. 5941-5944, Oct 2002.

[21] S. Ju, J.Li, N. Pimparkar, M. Alam, R.P.H. Chang and D.B. Janes, IEEE Transactions on Nanotechnology, vol. 6, no. 3, pp. 390-395, May 2007.

[22] Y.K. Tseng, C.J. Huang, H.M. Cheng, I.N. Lin, K.S. Liu and I.C. Chen, Adv. Funct. Mater., vol. 13, issue 10, pp. 811-814, Oct. 2003. 